\title{
Differences in cell wall of thin and thick filaments of cyanobacterium Aphanizomenon gracile SAG 31.79 and their implications for different resistance to Daphnia grazing
}

\author{
Lukasz WEJNEROWSKI, ${ }^{1 *}$ Slawek CERBIN, ${ }^{1}$ Maria K. WOJCIECHOWICZ, ${ }^{2}$ Marcin K. DZIUBA ${ }^{1}$ \\ ${ }^{1}$ Department of Hydrobiology, Faculty of Biology, Adam Mickiewicz University, Umultowska 89, 61-614 Poznań; ${ }^{2}$ Department of \\ General Botany, Faculty of Biology, Adam Mickiewicz University, Umultowska 89, 61-614 Poznań, Poland \\ *Corresponding author: wejner@amu.edu.pl
}

\begin{abstract}
Recent studies have shown that the filamentous cyanobacterium Aphanizomenon gracile Lemmermann, strain SAG 31.79, consists of two types of filaments that differ in thickness. These two types are known to vary in resistance to Daphnia magna grazing: thin filaments $(<2.5 \mu \mathrm{m})$ are more vulnerable to grazing than the thick ones $(>2.5 \mu \mathrm{m})$. In this study, we investigated whether the difference in the vulnerability to grazing of thin and thick filaments is a result of different thickness of their cell walls, a filament stiffness determinant. We expected thick filaments to have thicker cell walls than the thin ones. Additionally, we analysed whether cell wall thickness correlates with filament thickness regardless of the filament type. A morphometric analysis of cell walls was performed using transmission electron micrographs of ultra-thin sections of the batch-cultured cyanobacterial material. Our study revealed that the thin type of filaments had thinner cell walls than the thick filaments. Moreover, cell wall thickness was positively correlated with filament thickness. Transmission electron microscopy (TEM) observations also revealed that the thin type of filaments was often at different stages of autocatalytic cell destruction, which was mainly manifested in the increase in cell vacuolization and degradation of the cytoplasm content. Based on our findings, we assume that previously reported higher resistance of thick filaments to Daphnia grazing results from greater stiffness and excellent physiological conditions of thick filaments.
\end{abstract}

Key words: Daphnia grazing; cell wall thickness; transmission electron microscopy (TEM); physiological state; batch- and continuous-cultures; programmed cell death (PCD).

Received: November 2015. Accepted: April 2016.

\section{INTRODUCTION}

Interactions between cyanobacteria and their grazers have frequently been discussed as critical for aquatic ecosystems in terms of freshwater resources quality (Carpenter et al., 1995), ecosystems functioning (Chislock et al., 2013) or anthropogenic impact (Suikkanen et al., 2013). Large-bodied cladocerans, such as Daphnia, play an important role in lakes, as they are able to effectively control phytoplankton biomass (Lynch, 1980; Carpenter et al., 1991). However, filamentous cyanobacteria can limit the capability of Daphnia to reduce phytoplankton biomass, as filaments clog meshes in the filtration apparatus and inhibit daphnids' food ingestion (Gliwicz and Siedlar, 1980). In addition, filamentous cyanobacteria (especially Nostocales) often form irregular filament aggregates, which Daphnia may not be able to consume (Lynch, 1980). To some extent, daphnids can cope with cyanobacterial filaments by cleaning filter-screens by means of post-abdominal rejection movements (Burns, 1968). This results in the shortening of the filament length (Dawidowicz, 1990; Sikora and Dawidowicz, 2015). Dawidowicz (1990) also concludes that broken and there- fore shorter filaments are more available for daphnids as an additional food source. This assumption is consistent with the results of previous studies by Holm et al. (1983), who described the nature of Daphnia's feeding behaviour in the presence of cyanobacterial filaments. Individuals of Daphnia pulex Leydig were able to graze effectively only on single filaments or small fascicles of Aphanizomenon flos-aquae Ralfs ex Bornet \& Flahault $(<1.5$ $\mathrm{mm}$ ), whereas their ability to graze on large colonies or long filaments $(>1.5 \mathrm{~mm}$ ) was strongly limited. A similar trend was reported by Oberhaus et al. (2007), who found that Daphnia pulicaria Forbes is capable of effective grazing only on short (50-100 $\mu \mathrm{m})$ filaments of Planktothrix rubescens De Candolle ex Gomont. Quite recently, Bednarska et al. (2014) provided evidence that the consequences of the filament length for Daphnia can be manifested throughout the lifetime of these organisms. Daphnids exposed to longer ( $>50 \mu \mathrm{m})$ filaments of Cylindrospermopsis raciborskii (Woloszynska) Seenayya \& Subba Raju were smaller in size at the first reproduction and had a lower fecundity than the animals that fed on filaments shorter than $50 \mu \mathrm{m}$. All the above studies conclude that there is a strong dependence between the length of 
filaments and Daphnia's feeding efficiency. On the other hand, some studies do not support the above hypothesis. For example, Panosso and Lürling (2010) did not find any significant difference in the clearance rate of Daphnia magna exposed to long $(137.1 \pm 64.1 \mu \mathrm{m})$ versus short $(61.0 \pm 23.4 \mu \mathrm{m})$ filaments of C. raciborskii. Moreover, Chen et al. (2011) compared the length distributions of filamentous green alga Ulothrix in the lake and the gut content of Daphnia and found no clear evidence that daphnids tended to consume shorter filaments over the longer ones. The filaments of Ulothrix occurred at the similar range of length and frequency both in Daphnia's guts and the lake. With regard to the above examples, which showed that filaments length was insignificant for Daphnia, the question was addressed whether there is any other morphological factor that affects the feeding efficiency of Daphnia.

The role of filament thickness for Daphnia has been neglected in the studies of zooplankton-cyanobacteria interactions. According to Nadin-Hurley and Duncan (1976), the thickness of filaments is more significant than filaments length for limiting ingestion by daphnids. Recently, Wejnerowski et al. (2015) revealed that filamentous cyanobacterium Aphanizomenon gracile strain SAG 31.79 occurs in a wide range of filament thicknesses with two noticeable dominant types of filaments; thin and thick. The thin filaments are frequently deformed and look like monstrosities. Their occurrence may be related to nutrient deficiency at the stationary phase of a population growth. Such forms are found in nature during the collapse of the bloom. The variability of filament thickness is also found in nature, for example, Hašler and Pouličkova (2003) found that the thinner filaments were occurred when the phosphorous was in deficiency. However, our previous studies revealed that the filament thickness variability can also be attributed to Daphnia grazing (Wejnerowski et al., 2015). A two-day exposure of $A$. gracile cultures to large-bodied Daphnia magna resulted in the decrease in the number of thin filaments, but also in an increase of the thick filaments in cyanobacterial cultures. Changes in the filaments thickness distribution towards thicker filaments in the presence of Daphnia may suggest that daphnids are less effective in grazing on thick filaments. This result also brings the question whether the thickness of filaments is the sole determinant of filament's resistance to grazing. Perhaps, thick and thin filaments differ in physical attributes, especially in filament stiffness, and thus they have different resistance to grazing. Several authors have reported that not only the size or shape of food particles can influence Daphnia's feeding efficiency but also their stiffness (Burns, 1969; DeMott, 1995). This physical property in cyanobacterial filaments is mainly determined through the thickness and architecture of the cell wall (Hoiczyk and Hansel, 2000). The cell wall of cyanobacteria is generally composed of the external layer, outer membrane, and peptidoglycan layer (for more details see: Hoiczyk and Baumeister, 1995; Lee, 2008; Baulina, 2012). Particular components have various functions (Benz and Bauer, 1988; Hoiczyk and Baumeister, 1997). As far as filament stiffness is concerned, the most important component of the cell wall seems to be the peptidoglycan layer consisting of $\mathrm{N}$-acetylmuramic acid, N-acetylglucosamine, and amino acids (for more details see Woitzik et al., 1988).

In this study, we compared cell wall thickness of the thick and thin types of filaments of the batch-cultured cyanobacterium Aphanizomenon gracile strain SAG 31.79. We expected that the thick type of filaments $(>2.5$ $\mu \mathrm{m})$ would have thicker cell walls in comparison to the thin ones $(<2.5 \mu \mathrm{m})$. Based on this comparison, we would like to explain our earlier findings showing a greater resistance of thick filaments to Daphnia grazing than thin ones (Wejnerowski et al., 2015). We suspect that thickness-related resistance of cyanobacterial filaments to grazing is due to differences in their cell wall thickness. Probably, thin filaments can be grazed more effectively by daphnids because they have thinner cell walls and hence they are less rigid in comparison to thick filaments with thicker cell walls.

\section{METHODS}

\section{Aphanizomenon gracile strain SAG 31.79 and its characteristics}

In this study, we examined the filamentous cyanobacterium A. gracile strain SAG 31.79, free of the cylindrospermopsin and microcystin LR (Wejnerowski et al., 2015), acquired from the culture collection of algae (Sammlung von Algenkulturen - SAG) at the University of Göttingen. This strain of cyanobacterium ranges in filament thickness with two noticeable sizes of filaments: thin $(<2.5 \mu \mathrm{m})$ and thick $(>2.5 \mu \mathrm{m})$. The two groups were distinguished based on filament thickness distribution with a distinct border at $2.5 \mu \mathrm{m}$ (Wejnerowski et al., 2015). Both sizes of filaments possess taxonomic features typical for A. gracile (Komárek and Komárková, 2006). In general, these include straight or slightly curved filaments with elongated and narrowed terminal cells of a characteristic 'capitate' morphology, and barrel-shaped heterocytes. Akinetes were not observed in our cultures of this strain. In addition to common taxonomic features, thin filaments have specific vegetative cells, which have elongated and narrow shapes (Fig. 1), and did not exceed $2.5 \mu \mathrm{m}$ in thickness. In contrast, thick filaments have typical vegetative cells (Fig. 1). Moreover, heterocytes of thin filaments are often slightly elongated (Fig. 1). In order to unequivocally confirm that we have a single strain with two sizes of filaments in this strain (and not a mixture of 
two strains), single thick and thin filament specimen were isolated following the procedure described by $\mathrm{Za}$ pomělová et al. (2007) and transferred separately into sterile Petri dishes filled with a liquid WC medium (Guillard and Lorenzen, 1972). After a month of cultivation, all batch cultures contained both thick and thin filaments. This procedure enabled us to confirm that we had a single strain of cyanobacterium, which for some reasons forms two fractions of filaments.

\section{Growth and culture conditions}

Four batch cultures of A. gracile were grown in 250 $\mathrm{mL}$ Erlenmeyer flasks. Cultures were maintained in a phytotron (Conviron, Winnipeg, Canada) under a controlled temperature $\left(20 \pm 0.5^{\circ} \mathrm{C}\right)$, photoperiod $(16: 8$ light-dark cycle) and light intensity (44 $\mu \mathrm{mol}$ quanta $\mathrm{m}^{-2} \mathrm{~s}^{-1}$; measured by a light meter LI-192 quantum sensor; LI-COR Bio-Sciences, Lincoln, NE, USA). We monitored the growth of cyanobacterial filaments by chlorophyll fluorescence measurements (BioTek Synergy H1 Hybrid Reader; BioTek Instruments, Inc., Winooski, VT ,USA) since the beginning of the cultivation in order to assess the growth phases. During the stationary phase (day 30), the $2 \mathrm{~mL}$ samples were taken to characterize the filament thickness distribution in cultures. The thickness of 30 randomly selected filaments was measured per each sample

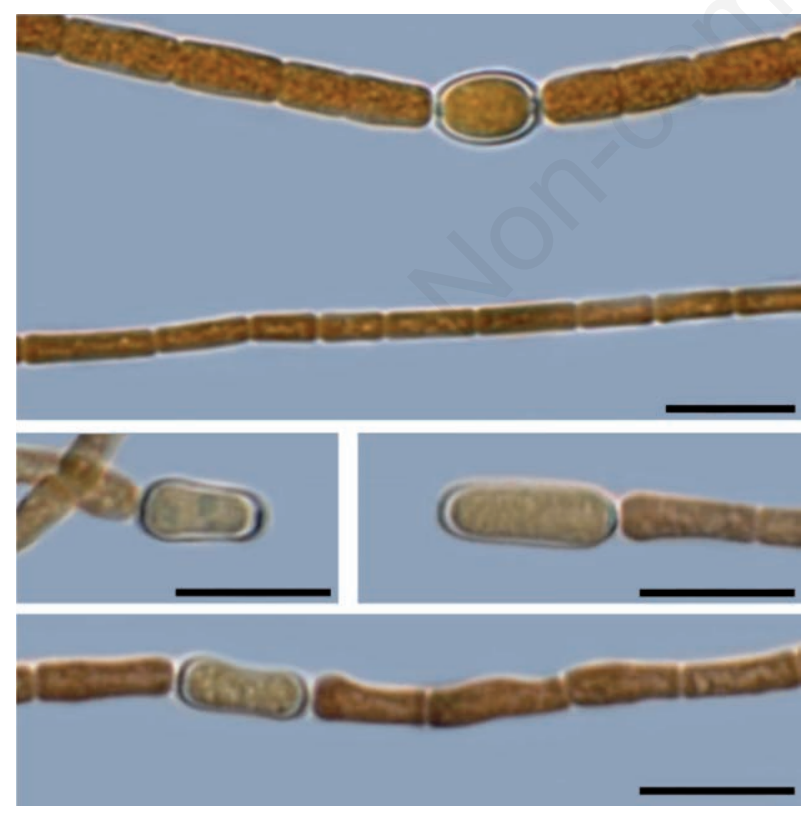

Fig. 1. Examples of thick and thin filaments of Aphanizomenon gracile strain SAG 31.79 (top panel) and examples of slightly elongated heterocytes occurred in thin filaments (middle and bottom panels). Examples originated from batch cultures. The magnification bar represents $10 \mu \mathrm{m}$ in each micrograph. at a total magnification 1000x using a light microscope Axioskop 2 mot plus (Carl Zeiss Light Microscopy, Jena, Germany) with a digital camera JENOPTIK ProgRes Speed $\mathrm{Xt}^{\text {core }} 3$ and ProgRes Image Capture Software (Jenoptik Optical Systems GmbH, Jena, Germany). Measurements were performed in the middle part of filaments.

\section{Preparation of samples for transmission electron microscopy and ultrastructural analyses}

Samples of A. gracile were concentrated by centrifugation for $30 \mathrm{~min}$ at $3000 \mathrm{rpm}$ (Rotina 380R centrifuge, Hettich, Kirchlengern, Germany). The pellets were fixed in $2 \%$ glutaraldehyde in $0.1 \mathrm{M}$ cacodylic buffer $(\mathrm{pH}=7.2)$ for $2 \mathrm{~h}$ at room temperature. Subsequently, they were rinsed three times in the same buffer and fixed again for $2 \mathrm{~h}$ at $4{ }^{\circ} \mathrm{C}$ in $1 \% \mathrm{OsO}_{4}$. Then, the pellets were counterstained with $2 \%$ solution of aqueous uranacyl acetate $(\mathrm{pH}=5.0)$, dehydrated in graded acetone series, and finally embedded in Spurr's epoxy resin (Spurr, 1969). Ultra-thin sections $(90 \mathrm{~nm})$ were cut with a diamond knife with an Ultracut S ultramicrotome (Leica-Reichert, Bensheim, Germany) and attached to multi-slots specimen grids. Post-staining of the ultra-thin sections was performed in uranacyl acetate and lead citrate for $20 \mathrm{~min}$.

To compare cell wall thicknesses between the two types of filaments in the strain SAG 31.79, photos of $A$. gracile's filaments were taken using a transmission electron microscope JEM 1200 EXII (JEOL, Japan) at acceleration of $80 \mathrm{kV}$ and at a total magnification 15000x. This part of work was performed in the Laboratory of Electron and Confocal Microscopy at Adam Mickiewicz University in Poznań (Poland). The cell wall thickness of 46 filaments was measured using ProgRes image capture software (JENOPTIK Optical Systems GmbH, Germany). In addition, the thickness of filaments was separately measured in order to obtain 16 thick filament specimens $(>2.5 \mu \mathrm{m})$ and 30 filament specimens thinner than $2.5 \mu \mathrm{m}$ (the thin type).

\section{Statistical analyses}

To test whether the thick and thin filaments in batch cultures differ from one another with regard to the thickness of their cell walls, we used Student t-test with prior examination of test's assumptions. Having measured the whole range of filament thickness of $A$. gracile in batch cultures, we also checked whether cell wall thickness correlates with filament thickness. For this purpose, a Spearman Rank correlation was computed. The data of filament thickness of $A$. gracile in batch cultures were visualized as a histogram. All the analyses were performed at a significance level of $\mathrm{P}=0.05$ using the $\mathrm{R}$ statistical software version 3.0.2 (R Core Team, 2013), which is available under general public licence. 


\section{RESULTS}

After 30 days of cultivation, the fraction of thin filaments $(<2.5 \mu \mathrm{m})$ distinctly dominated over the fraction of thick ones $(>2.5 \mu \mathrm{m})$ (Fig. 2a). Thin filaments constituted $82.5 \%$ while the thick ones accounted for $17.5 \%$. With regard to the analysis of cell wall thickness in two fractions of filaments originating from batch cultures, the Student's $t$-test revealed that thin filaments had significantly thinner cell walls $(0.032 \pm 0.0062 \mu \mathrm{m}$; mean and standard deviation) than those from the fraction of filaments thicker than $2.5 \mu \mathrm{m}(0.045 \pm 0.0066 \mu \mathrm{m}), \mathrm{t}=-6.55, \mathrm{df}=44, \mathrm{P}<0.0001$ (Fig. 2b). The positive correlation between cell wall thickness and filament thickness was significant (Spearman Rank: $R=0.84, n=46, \mathrm{P}<0.0001$ ) (Fig. 2c).

In addition to the analysis of cell wall thickness, we also examined other cellular components. Observations of electron micrographs did not reveal any well pronounced differences in ultrastructure of the cells between thick and thin filaments of $A$. gracile. Characteristic components of the cyanobacterial protoplast were noted in both sizes of filaments, in particular carboxysomes Cs, nucleoplasm $\mathrm{N}$, thylakoids $\mathrm{T}$ with anchored phycobilisomes, cyanophycin granules $\mathrm{Cy}$, electron-dense bodies $\mathrm{Eb}$, and residual holes of polyphosphate bodies $\mathrm{Pb}$, (Figs. 3,4 , and 5). However, it was also observed that thin filaments and especially these extremely thin specimens (1.8$1.4 \mu \mathrm{m}$ ) were often at various stages of destruction (Fig. 5). In such filaments, vacuolization (V) in the cells was markedly increased and vacuoles occupied a relatively high percentage of the cells. Similar trend in cell destruction was also found in some cells that developed into heterocytes (Fig. 6a).

\section{DISCUSSION}

As expected, two fractions of $A$. gracile's filaments from strain SAG 31.79 had different cell wall thickness. Thick filaments $(>2.5 \mu \mathrm{m})$ had thicker cell walls than the thin filaments $(<2.5 \mu \mathrm{m})$ (Fig. 2b). Cell wall thickness was also positively correlated with filament thickness (Fig. 2c). In addition, transmission electron microscopy (TEM) observations revealed that the thin type of filaments, especially these extremely thin (1.8-1.4 $\mu \mathrm{m})$, often showed some symptoms of autolytic cell destruction (Fig. 5). Since cell wall thickness determines the stiffness of cyanobacterial filaments (Hoiczyk and Hansel, 2000) and thin filaments of $A$. gracile were probably in a worse condition, it is reasonable to expect that filaments from the thick fraction are more rigid than thin filaments. Hence, thick filaments may also have a greater resistance to grazing by filter-feeding zooplankton.

Our findings can provide an answer as to why the filament thickness distribution of $A$. gracile (the same strain which was examined in this study) changed to thicker fil- aments in the presence of Daphnia (Wejnerowski et al., 2015). Since thick filaments are stiffer and 'healthy' without signs of autolytic cell destruction (Figs. 3 and 4), we suspect that thick filaments may be also less susceptible to damages during the physical contact with daphnids and, consequently, they may be consumed by daphnids to a smaller extent than thin filaments. Although Daphnia can partly remove cyanobacterial filaments from the filtering apparatus by movements of post-abdominal claw (Gliwicz and Siedlar, 1980), thick filaments may substantially limit
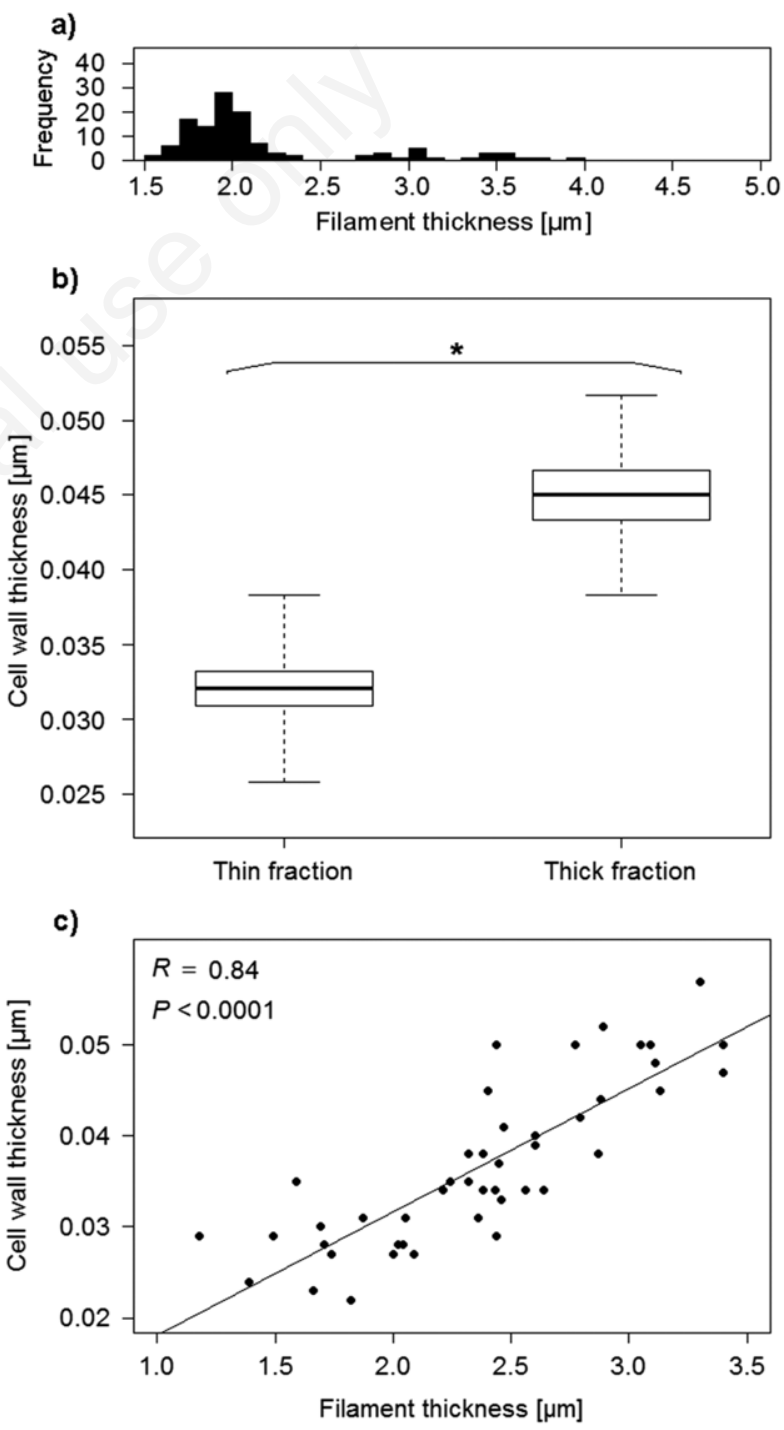

Fig. 2 The frequency distribution of filament thickness of $A$. gracile after 30 days of cultivation in batch cultures (a), the differences in cell wall thickness between thin and thick filaments of $A$. gracile highlighted by Student's $t$-test $(\mathrm{t}=-6.55, \mathrm{P}<0.0001)$ (b), and relationship between cell wall thickness and filament thickness with results of the Spearman Rank Correlation, $R$ (c). 

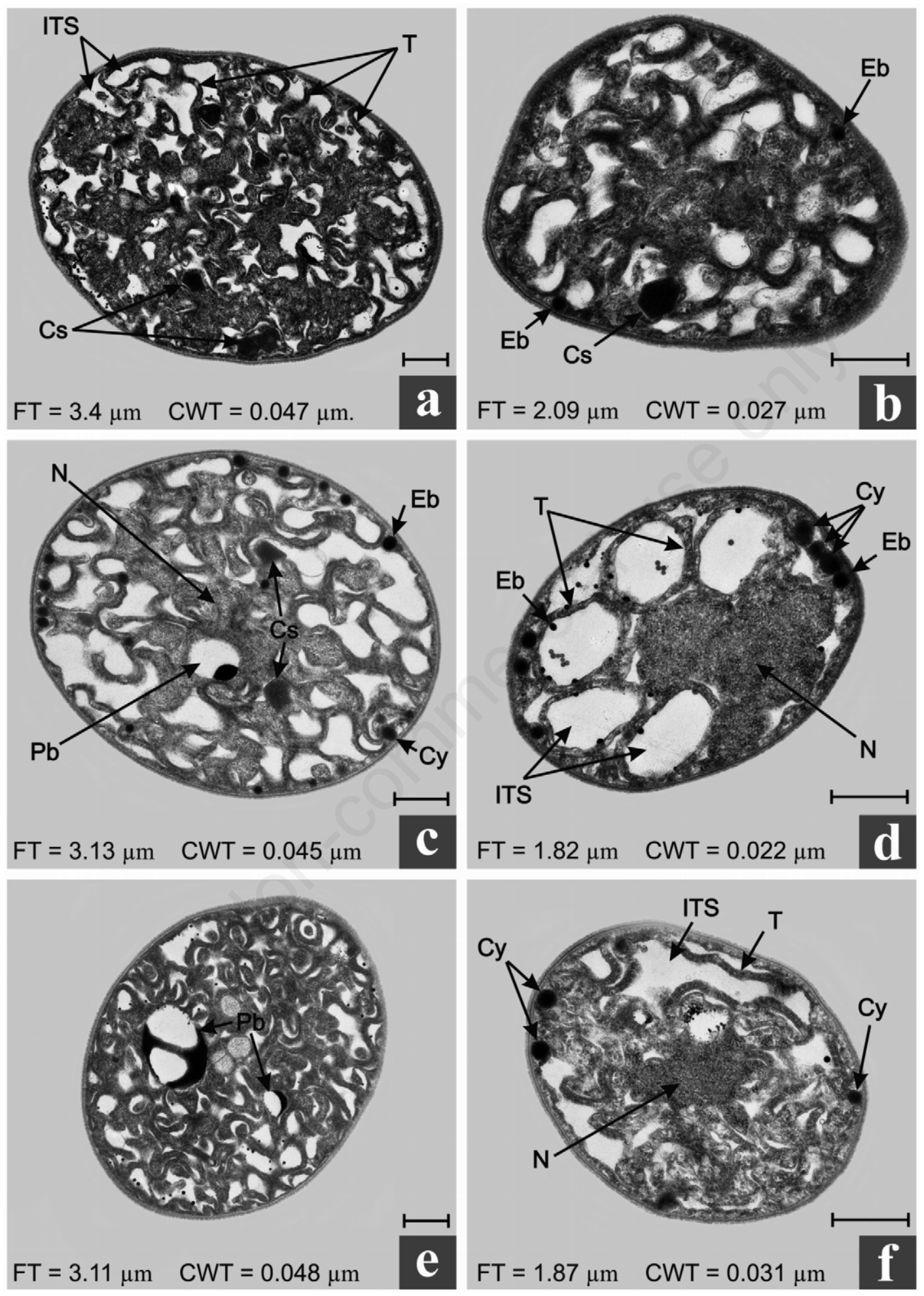

Fig. 3 Cross-sections of A. gracile's filaments showing ultrastructure of cells belonging to thick $(>2.5 \mu \mathrm{m}$; a, b, c) and thin $(<2.5 \mu \mathrm{m}$; $\mathrm{d}$, e, f) fraction of filaments. Measurements of filament thickness (FT) and cell wall thickness (CWT) are given at the bottom of each micrograph. Eb, electron-dense bodies; Cs, carboxysomes; Cy, cyanophycin granules; ITS, intrathylakoid spaces; N, nucleoplasm; T, thylakoids; $\mathrm{Pb}$, residual holes of polyphosphate bodies. Scale bars: $0.5 \mu \mathrm{m}$. 
the efficiency of this process. In addition, filamentous cyanobacteria often form irregular aggregates inside the filtering apparatus of Daphnia (Hartmann and Kunkel, 1991), and the ability of Daphnia to shred them may be reduced due to entanglements of thick and stiff filaments.
The differences in filament thickness and cell wall thickness observed in two fractions of $A$. gracile, the physiological state of their filaments as well as their different resistance to grazing (Wejnerowski et al., 2015) provide further insight into the understanding of Daphnia's feeding
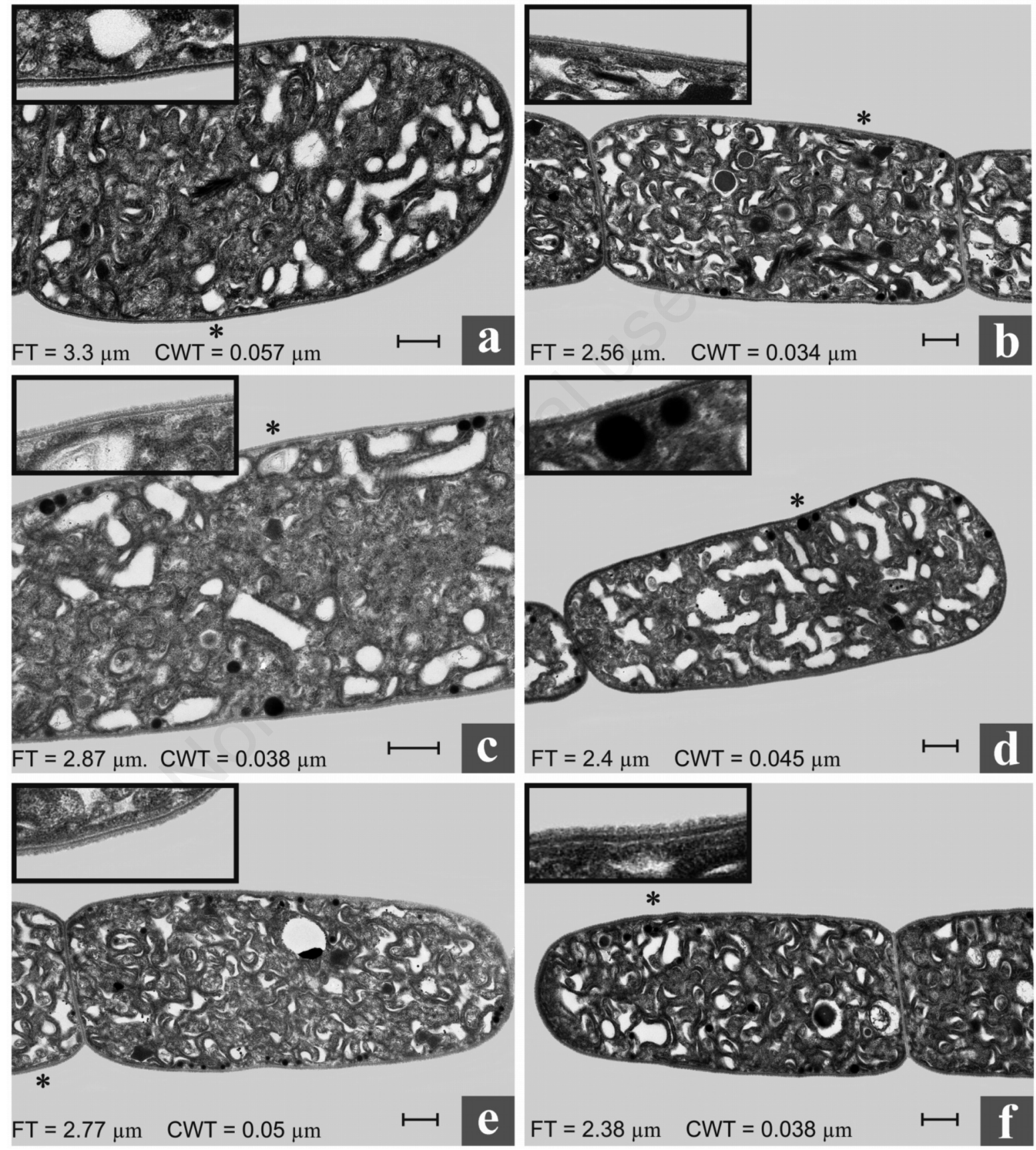

*
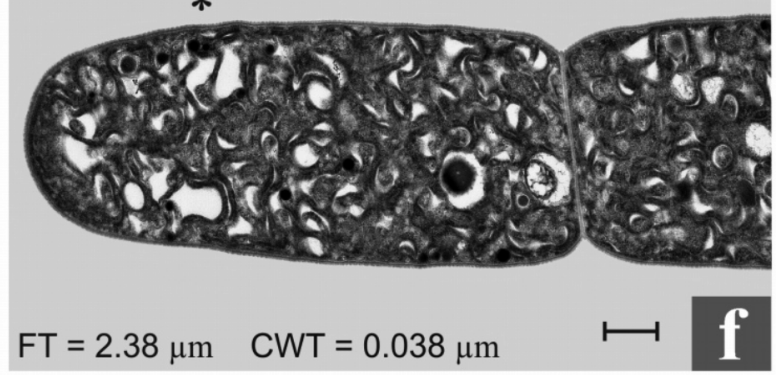

Fig. 4 Longitudinal sections of $A$. gracile's filaments showing ultrastructure of cells belonging to thick ( $>2.5 \mu \mathrm{m}$; a, b, c, d) and thin $(<2.5 \mu \mathrm{m}$; e, f) fraction of filaments. Measurements of filament thickness (FT) and cell wall thickness (CWT) are given at the bottom of each micrograph. Star on each micrograph indicates the location measurement of cell wall thickness. The inset in the upper left corner of each micrograph indicates structure of the cell wall. Scale bars: $0.5 \mu \mathrm{m}$. 
efficiency on filamentous cyanobacteria. Numerous studies have demonstrated that the effectiveness of this process depends on several factors, such as the concentration of filaments (Gliwicz, 1990a), filament length (Dawidowicz, 1990; Oberhaus et al., 2007), and filament thickness (Nadin-Hurley and Duncan, 1976). The results presented in this paper together with the previously observed effect of Daphnia grazing on A. gracile's filament thickness distribution (Wejnerowski et al., 2015), provide evidence that Daphnia's feeding activity may be also limited by filament stiffness and the physiological state of filaments. It is in accordance with the claim that physical properties of food particles (the architecture of the cell wall and stiffness) play a crucial role in the feeding efficiency of Daphnia (Burns, 1969). The importance of food particle stiffness was also highlighted by DeMott (1995), who has revealed that the feeding efficiency of Daphnia decreases with the increase of stiffness or hardness of food particles. 'Naked' and 'soft' green algae like Chlamydomonas sp. and Eudorina $s p$. were readily ingested by daphnids, unlike stiff diatom Cyclotella meneghiniana Kützing, dinoflagellate Peridnium sp., and the stiffest polystyrene beads. On the other hand, the occurrence of thin filaments with noticeable signs of autolytic cell destruction observed in this study (Fig. 5) and filaments' increased vulnerability to grazing (Wejnerowski et al., 2015) support the view that the physiological state of cyanobacterial filaments is important for Daphnia's feeding efficiency. This aspect was examined and observed for the first time in Aphanizomenon flos-aquae by Gliwicz (1990a; 1990b). The author reported that the exposure of cultures being in a poor physiological condition to Daphnia grazing caused a strong reduction in the concentration and length of filaments, whereas no effect of grazing was observed in cultures in the superior physiological condition.

Apart from the comparison of cell wall thickness in thick and thin filaments of A. gracile's we were also interested in the nature of the occurrence of these two sizes of filaments. The analysis of the filament thickness distribution revealed that in batch cultures thin filaments $(<2.5 \mu \mathrm{m})$ vividly dominated over the thick ones $(>2.5$ $\mu \mathrm{m})$ (Fig. 2a). In batch cultures, microbes go through all the growth phases (including lag, exponential, stationary, and death phases), and hence it is impossible to maintain cultures at the constant concentration of nutrients, light intensity or $\mathrm{pH}$ (Villadsen et al., 2011). Thus, we suspect that the occurrence of two sizes of filaments with a clear prevalence of thin and untypical filaments in batch cultures was closely related to the unstable growth conditions. Our prediction is in agreement with the general opinion that stress factors (such as light intensity fluctuations, nutrient starvation or $\mathrm{pH}$ changes) may promote the increase of population heterogeneity among a single cyanobacterial strain (Baulina, 2012). It seems a plausible explanation, especially if we take into account that extremely thin filaments $(1.4-1.8 \mu \mathrm{m})$ were often at the stage of destructive changes, and these changes were noted as destruction of the thylakoids and cytoplasm content, with autolysis of nucleoplasm (Fig. 8). In addition, vacuolization in such filaments was advanced and occupied a relatively high parts of cells. These symptoms are similar to
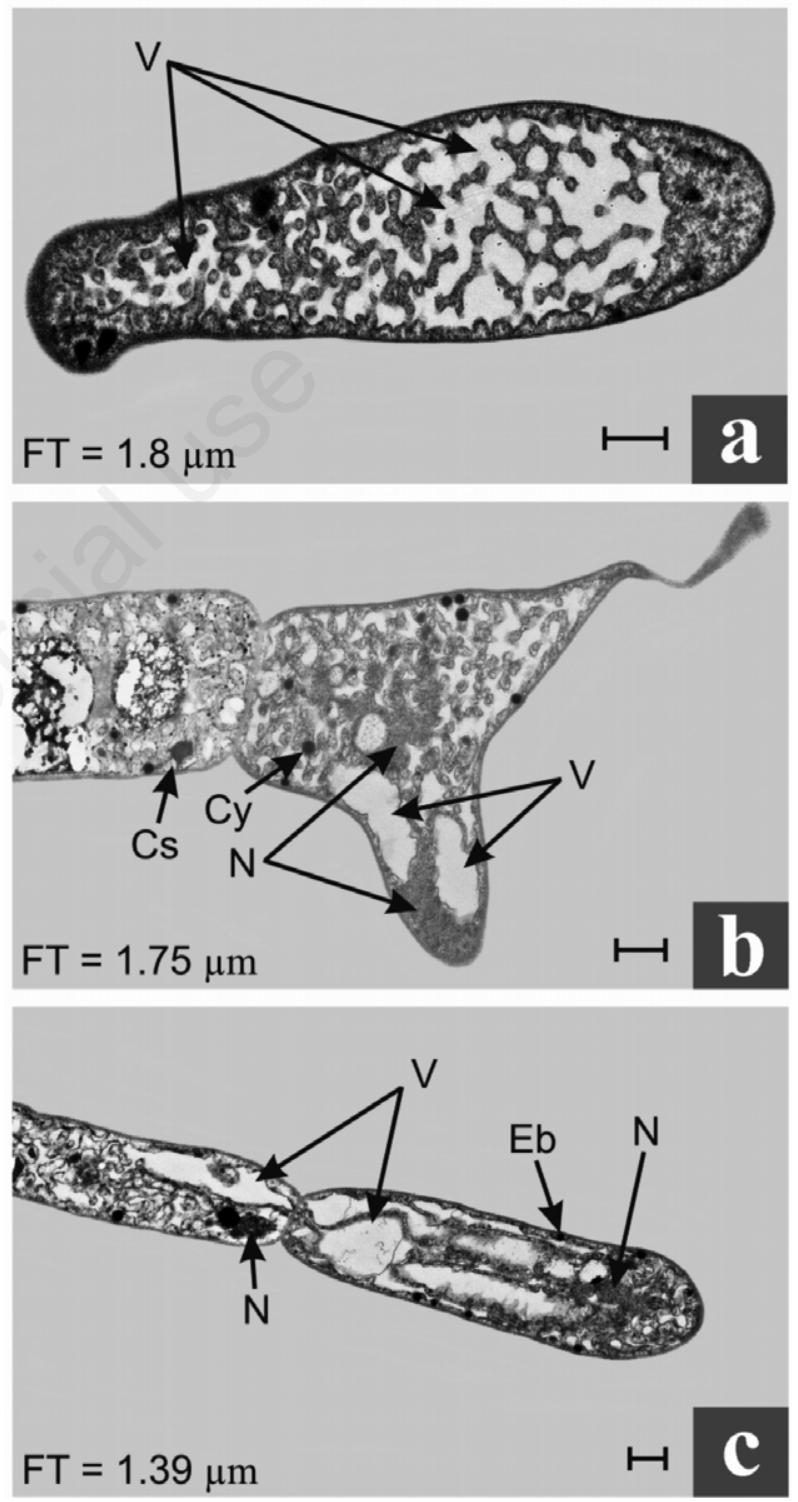

Fig. 5 Longitudinal sections of $A$. gracile's filaments showing destructive changes inside the cells belonging to thin $(<2.5 \mu \mathrm{m})$ fraction of filaments. Measurements of filament thickness (FT) are given at the bottom left corner of each micrograph. Cell wall thickness was not measured in filaments with signs of autocatalytic destructions. Eb, electron-dense bodies; Cs, carboxysomes; $\mathrm{Cy}$, cyanophycin granules; $\mathrm{N}$, nucleoplasm; V, increasing vacuolization. Scale bars: $0.5 \mu \mathrm{m}$. 
those observed by Janson et al. (1995) and Berman-Frank et al. (2004) in several strains of the cyanobacterium Trichodesmium spp., and may indicate involvement of programmed cell death (PCD).

Another explanation of the existence of two types filaments is related to the advanced age of this strain, which has been cultured under laboratory conditions for more than 50 years (for more details see EPSAG Home Page). Perhaps, the observed variability in filaments' morphology may be an interesting case of adaptation of relatively complicated cyanobacterial type to long-term cultivation in vitro and can be used as a model for solution of various problems connected with adaptation mechanisms to stable cultivation conditions in strain col- lections. We take into account such a scenario because several newly isolated strains of A. gracile (2012-2014 years), which are deposited in the library of cyanobacterial strains held at the Department of Hydrobiology (Adam Mickiewicz University in Poznan), have no abnormal filaments in batch cultures. Therefore, it is possible that the old strain of $A$. gracile SAG 31.79 has two types of filaments due to the strong regress of morphological and cellular components. This scenario could be supported by studies of Lee (2008), who found abnormal changes in morphology and reproduction of several isolates of red algae (phylum Rhodophyta) after long-term laboratory cultivation.

On the other hand, the presence of grazers in aquatic
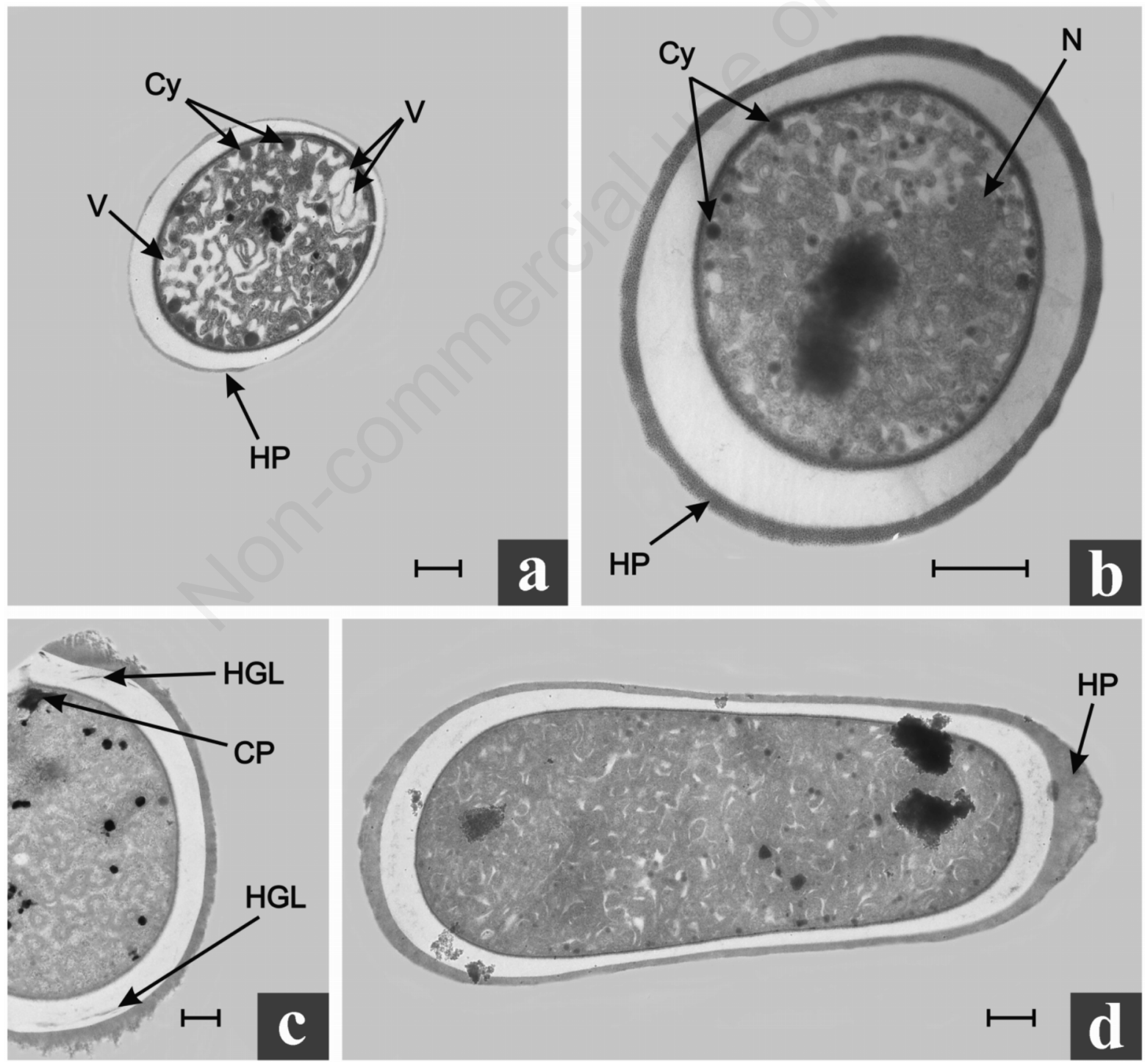

Fig. 6 Cross (a, b, c,) and longitudinal (d) sections of A. gracile's heterocytes. CP, cyanophycin plug; Cy, cyanophycin granules; HP, heterocyte envelope polysaccharide; HGL, heterocyte glycolipid layer; N, nucleoplasm; V, increasing vacuolization. Scale bars: $0.5 \mu$ m. 
ecosystems is a one of several major factors shaping the morphology, 'behaviour' or even physiology of phytoplankton organisms (Hessen and van Donk, 1993; Fiałkowska and Pajdak-Stós, 1997; Jang et al., 2007), while phytoplankton isolates are maintained under laboratory conditions without natural grazers. Thus, a long-term absence of grazers may remove the selection against mutation leading to increase the variability in filament thickness and abnormalities in cyanobacterial cultures. This view may be supported by previous studies of Cerbin et al., 2013, in which the thickness of the same strain of A. gracile increased after a 12-day exposure to daphnids and infochemicals of these animals.

\section{CONCLUSIONS}

The examination of the filaments ultrastructure of $A$. gracile's strain SAG 31.79 revealed that two sizes of filaments in this strain differ in cell wall thickness. More specifically, the thin type of filaments $(<2.5 \mu \mathrm{m})$ had thinner cell walls in comparison to the thick type $(>2.5 \mu \mathrm{m})$. In addition, extremely thin filaments $(1.8-1.4 \mu \mathrm{m})$ had symptoms of destructive changes, which were manifested in the destruction of thylakoids, cytoplasm and nucleoplasm content. These findings allow us to better understand and explain different resistance of the two types of filaments to grazing by Daphnia, as it was observed in the previous study. In our opinion, lower resistance to grazing of thin filaments resulted from their lower stiffness as well as the inferior physiological state of filaments. Probably, such filaments are easily eliminated from the population and in consequence difficult to find in field samples.

Our results also demonstrate that the occurrence of thin and abnormal filaments in the strain of cyanobacterium can be either at their senescence stages that appear during the bloom collapse or it is a phenomenon characteristic for this particular strain maintained in laboratory culture for many years. Further research is needed to investigate the occurrence of abnormal filaments in other cyanobacterial strains. Moreover, more attention should be paid to abnormal filaments found in nature.

\section{ACKNOWLEDGMENTS}

The financial support was provided by the National Science Centre in Poland by grant No. UMO2012/07/N/NZ8/00166. The authors would like to thank Professor Jiři Komárek (Academy of Sciences of the Czech Republic, and University of South Bohemia), Dr. Aleksandra Pełechata and Dr. Mikołaj Kokociński (Adam Mickiewicz University) for their comments and useful discussion, and Dr. Grzegorz Nowicki for help in estimation of cyanobacteria growth. The authors would also like to thank Magdalena Wesołowska for linguistic correction of the manuscript.

\section{REFERENCES}

Baulina OI, 2012. Ultrastructural plasticity of cyanobacteria. Springer Verlag, Berlin: 204 pp.

Bednarska A, Pietrzak B, Pijanowska J, 2014. Effect of poor manageability and low nutritional value of cyanobacteria on Daphnia magna life history. J Plankton Res. 36:838-847.

Benz R, Bauer K, 1988. Permeation of hydrophilic molecules through the outer membrane of gram-negative bacteria. Review of bacterial porins. Eur. J. Biochem. 176:1-19.

Berman-Frank I, Bidle KD, Haramaty L, Falkowski PG, 2004. The demise of the marine cyanobacterium, Trichodesmium spp., via an autocatalyzed cell death pathway. Limnol. Oceanogr. 49:997-1005.

Burns CW, 1968. Direct observation of mechanisms regulating feeding behavior of Daphnia in lakewater. Int. Rev. Ges. Hydrobiol 53:83-100.

Burns CW, 1969. Particle size and sedimentation in the feeding behavior of two species of Daphnia. Limnol. Oceanogr. 14:392-402.

Carpenter SR, Christensen DL, Cole JJ, Cottingham KL, He X, Hodgson JR, Kitchell JF, Knight SE, Pace ML, Post DM, Schindler DE, Voichick N, 1995. Biological control of eutrophication in lakes. Environ. Sci. Technol. 29:784-786.

Carpenter SR, Frost TM, Kithchell JF, Kratz TK, Schindler DW, Shearer J, Sprules WG, Vianni MJ, Zimmermann AP, 1991. Patterns of primary production and herbivory in 25 North American lake ecosystems, p. 67-96. In: J. Cole, G. Lovette, S. Frindlay (eds.), Comparative analyses of ecosystems: patterns, mechanisms, and theories. Springer, New York.

Cerbin S, Wejnerowski L, Dziuba MK, 2013. Aphanizomenon gracile increases in width in the presence of Daphnia. A defence mechanism against grazing? J. Limnol. 72:e41.

Chen F, Gulati RD, Li J, Zhengwen L, 2011. A comparison of the size distribution of the filamentous green alga Ulothrix in Daphnia guts and lake water from Lake Taihu, China. J. Plankton Res. 33:1274-1283.

Chislock FM, Sarnelle O, Olsen BK, Doster E, Wilson AE, 2013. Large effects of consumer offense on ecosystem structure and function. Ecology 94:2375-2380.

Dawidowicz P, 1990. The effect of Daphnia on filament length of blue-green algae. Hydrobiologia 191:265-268.

DeMott WR, 1995. The influence of prey hardness on Daphnia's selectivity for large prey. Hydrobiologia 307:127-138.

Fiałkowska E, Pajdak-Stós A, 1997. Inducible defence against ciliate grazer Pseudomicrothorax dubius, in two strains of Phormidium (cyanobacteria). Proc. Biol. Sci. 264:937-941.

Gliwicz ZM, 1990a. Daphnia growth at different concentrations of blue-green filaments. Arch. Hydrobiol. 120:51-65.

Gliwicz ZM, 1990b. Why do cladocerans fail to control algal blooms? Hydrobiologia 200/201:83-97.

Gliwicz ZM, Siedlar E, 1980. Food size limitation and algae interfering with food collection in Daphnia. Arch. Hydrobiol. 88:155-177.

Guillard RRL, Lorenzen CJ, 1972. Yellow-green algae with chlorophyllide $c$. J. Phycol. 8:10-14.

Hartmann HJ, Kunkel DD, 1991. Mechanisms of food collection in Daphnia. Hydrobiologia 225:129-154.

Hašler P, Pouličkova A, 2003. Diurnal changes in vertical distribution and morphology of a natural population of 
Planktothrix agardhii (Gom.) Anagnostidis et Komarek (Cyanobacteria). Hydrobiologia 506:195-201.

Hessen DO, Van Donk E, 1993. Morphological changes in Scenedesmus induced by substances realised from Daphnia. Arch. Hydrobiol. 127:129-140.

Hoiczyk E, Baumeister W, 1995. Envelope structure of four gliding filamentous cyanobacteria. J. Bacteriol. 177:2387-2395.

Hoiczyk E, Baumeister W, 1997. Oscillin, an extracellular $\mathrm{Ca}^{2+}$ binding glycoprotein essential for the gliding motility of cyanobacteria. Mol. Microbiol. 26:699-708.

Hoiczyk E, Hansel A, 2000. Cyanobacterial cell walls: news from an unusual prokaryotic envelope. J. Bacteriol. 182:1191-1199.

Holm NP, Ganf GG, Shapiro J, 1983. Feeding and assimilation rates of Daphnia pulex fed Aphanizomenon flos-aquae. Limnol. Oceanogr. 28:677-687.

Jang MH, Jung JM, Takamura N, 2007. Changes in microcystin production in cyanobacteria exposed to zooplankton at different population densities and infochemical concentrations. Limnol. Oceanogr. 52:1454-1466.

Janson S, Siddiqui PJA, Walsby AE, Romans KM, Carpenter EJ, Bergman B, 1995. Cytomorphological characterization of the planktonic diazotrophic cyanobacteria Trichodesmium spp from the Indian Ocean and Caribbean and Sargasso Seas. J. Phycol. 31:463-477.

Komárek J, Komárková J, 2006. Diversity of Aphanizomenonlike cyanobacteria. Czech Phycol. 6:1-32.

Lee RE, 2008. Phycology. 4. Cambridge University Press, Cambridge: $560 \mathrm{pp}$.

Lynch M, 1980. Aphanizomenon blooms: alternate control and cultivation by Daphnia pulex, p. 229-304. In: W.C. Kerfoot (ed.), Evolution and ecology of zooplankton communities. University Press of New England, Hanover.

Nadin-Hurley CM, Duncan A, 1976. A comparison of daphnid gut particles with the sestonic particles present in two
Thames Valley reservoirs throughout 1970 and 1971. Freshwater Biol. 6:109-123.

Oberhaus L, Gélinas M, Pinel-Alloul B, Ghadouani A, Humbert JF, 2007. Grazing of two toxic Planktothrix species by Daphnia pulicaria: potential for bloom control and transfer of microcystins. J. Plankton. Res. 29:827-838.

Panosso R, Lürling M, 2010. Daphnia magna feeding on Cylindrospermopsis raciborskii: the role of food composition, filament length and body size. J. Plankton Res. 32:1393-1404.

R Core Team, 2013. R: A language and environment for statistical computing. R. Foundation for Statistical Computing, Vienna, Austria. Available from: http://www.R-project.org/

Sikora A, Dawidowicz P, 2015. Breakage of cyanobacterial filaments by small- and large-sized Daphnia: are there any temperature-dependent differences? Hydrobiologia DOI: 10.1007/s10750-015-2436-5.

Spurr AR, 1969. A low-viscosity epoxy resin embedding medium for electron microscopy. J. Ultrastruct. Res. 23:31-43.

Suikkanen S, Pulina S, Engström-Öst J, Lehtiniemi M, Lehtinen S, Brutemark A, 2013. Climate change and eutrophication induced shifts in northern summer plankton communities. Plos One 8:e66475.

Villadsen J, Nielsen J, Lidén G, 2011. Bioreaction engineering principles. 3. Springer: $281 \mathrm{pp}$.

Wejnerowski L, Cerbin S, Dziuba MK, 2015. Thicker filaments of Aphanizomenon gracile are more harmful to Daphnia than thinner Cylindrospermopsis raciborskii. Zool. Stud. 54:2.

Woitzik D, Weckesser J, Jürgens UJ, 1988. Isolation and characterization of cell wall components of the unicellular cyanobacterium Synechococcus sp. PCC 6307. J. Gen. Microbiol. 134:619-627.

Zapomělová E, Řeháková K, Znachor P, Komárková J, 2007. Morphological diversity of coiled planktonic types of the genus Anabaena (cyanobacteria) in natural populations taxonomic consequences. Cryptogamie Algol. 28:353-371. 